\title{
Genetic Diversity Associated with Eco-geographical Parameters, Morphological Characteristics and Soil Analyzes of Common Vetch (Vicia sativa L.) in Algeria
}

\author{
H. Bougrine ${ }^{1}$, A. Mebarkia ${ }^{1}$, S. Bechkri²
}

10.18805/ag.DF-404

\begin{abstract}
Background: In the present study, we have set a goal, to study the genetic variability and phylogenetic affinities of 26 spontaneous Vicia sativa L. accessions collected in Algeria, as part of the recovery and enhancement of the local genetic heritage and its integration into the breeding and varietal creation programs.

Methods: Morphological traits, performance parameters and phenological stages of each accession were tracked during an experimental test in pots under greenhouse conditions from December 29, 2019 to June 1, 2020. An eco-geographical characterization of samples was also carried out through geographical coordinates. On the other side and for the first time in Algeria, soil analyses of each site were undertaken.

Result: The phylogenetic study of accessions confirm the taxonomic complexity of the group $V$. sativa $L$. According to the principal component analyses and kruskal-Wallis test, the most segregating variables with the highest values and the largest $\mathrm{K}$ variance ratios are most of the attributes associated with the flower, pod and seed. The association of the two dissimilarity matrix carried out by a Mantel test between the morphological and eco-geographic parameters showed a significant effect with a $p$ value $=0.004$ at the threshold of alpha $=0.05$ and a correlation coefficient $r(\mathrm{AB})=0.156$.
\end{abstract}

Key words: Common vetch, Eco-geographical parameters, Genetic diversity, Germplasm, Morphological traits, Soil analysis.

\section{INTRODUCTION}

Annual species of the genus Vicia L. have been used in agriculture for a very long time. It is known that the species $V$. sativa $L$, was cultivated during Roman times and used as a green manure and fodder for cattle feed (Erskine et al. 1994). Indeed, only one species and one variety of vetch is used in the different agro-ecological zones of Algeria: $V$. sativa L. var. Languedoc. This culture has not shown any real opportunities for adaptation in regions with high contrasts due to a lack of specific and varietal diversity (Mebarkia 2007).

Common vetch ( $V$. sativa L.) is one of the most genetically and phenotypically variable species of Vicia (Firincioglu et al. 2009). It is an important self-pollinating annual forage legume and commonly grown winter cover crop (Sattell et al. 1998). It is also used for pasture, silage and hay (Dong et al. 2017). Vetch is now widespread throughout many parts of the world, including the Mediterranean Basin, West and Central Asia, East Asia, India and the United States (Sattell et al. 1998). As a legume crop, it grows well in mixtures with cereals and has the ability to fix nitrogen (Fracchiolla et al. 2018). In order to improve plant performance under different environmental constraints, information on the magnitude of genetic variation will provide a basis for deciding on selection of traits and associated breeding strategies (Annese et al. 2006; Firincioglu et al. 2009; Dong 2019).

In the context of climatic transition and increased food demand, our study aimed to analyze the morphological and agronomical traits of 26 spontaneous accessions belonging
${ }^{1}$ Laboratoire d'amélioration et de développement de la production végétale et animale (LADPVA), Université Ferhat Abbas Sétif 1, Algeria.

${ }^{2}$ Laboratoire de Génétique Biochimie et Biotechnologies Végétales. Université Frères Mentouri Constantine 1,Algeria.

Corresponding Author: H. Bougrine, Laboratoire d'Amélioration et de Développement de la Production Végétale et Animale (LADPVA), Université Ferhat Abbas Sétif 1, Algeria.

Email: bougrinehoucine77@gmail.com

How to cite this article: Bougrine, H., Mebarkia, A. and Bechkri, S. (2022). Genetic Diversity Associated with Eco-geographical Parameters, Morphological Characteristics and Soil Analyzes of Common Vetch (Vicia sativa L.) in Algeria. Agricultural Science Digest. DOI: 10.18805/ag.DF-404.

Submitted: 10-09-2021 Accepted: 13-12-2021 Online: 16-01-2022

to the species $V$. sativa $L$. collected from 12 sites in the province of Sétif in Algeria. The present work was undertaken (i) to study the extent of the genetic diversity and evaluate the phylogenetic affinities of these accessions and (ii) to determine their habitat preferences and develop geographic distribution maps in order to facilitate the use of this germplasm in breeding programs.

\section{MATERIALS AND METHODS}

Plant material

The current study concerns 26 spontaneous populations of V. sativa L. collected across 12 different geographic regions 
in the province of Sétif (eastern Algeria). The mature and dry pods of each plant were collected individually and stocked in paper bags; these are labelled, tightly sealed and kept at room temperature until used. A soil sample (0$20 \mathrm{~cm}$ ) was taken for each site.

\section{Experimental protocol}

An experimental pot trial was conducted from December 29,2019 to June $1^{\text {st }}, 2020$ under greenhouse conditions at the experimental farm of Ferhat Abbas Sétif University $\left(36^{\circ} 12^{\prime} 05.7^{\prime \prime} \mathrm{N} 5^{\circ} 21^{\prime} 58.0^{\prime \prime} \mathrm{E}\right)$. Each pot contained gravel at the bottom, $1 / 3$ of commercial soil and topsoil screened using a sieve with stitches of about $3 \mathrm{~mm}$. A mechanical pregermination test (scarification) was done in vitro in order to overcome the stiffness of the cuticle of vetch species including those of $V$. sativa L. 7 scarified seeds from each accession were soaked in distilled water for 24 hours before they were left to germinate on Wattman paper in petri dishes, in the dark and at room temperature. The seeds were considered sprouted and ready to be sown when the length of the rootlet approached the diameter of the seed. Only three seeds from each accession have been transplanted which gives us a total of 78 individuals. The arrangement of the pots in the greenhouse was carried out according to an experimental design in total randomization.

\section{Morphological parameters}

A total of 100 morphological traits were observed in this study at 8 phenological stages through a binocular magnifier and a digital caliper. Characters were selected from taxonomic studies, descriptors of UPOV for common vetch (1988) and also from own and personal observation.

The identification of the species was made using the key of Quezel and Santa (1962). After the accessions maturity, the soil was sifted to check for the presence of amphicarpic pods.

\section{Eco-geographic parameters}

Latitude, longitude and altitude of each site were collected using a Global Positioning System (GPS) and Google Earth Pro application. Soil analyses of samples taken from each site visited have focused on $\mathrm{pH}$, conductivity, total limestone (Bernard's calcimeter method), phosphorus (Olsen method), nitrogen (kjeldal method), organic carbon and organic matter (Anne's method).

\section{Statistical analysis}

Data collected were processed using a Hierarchical Classification Test, Principal Component Analysis (PCA), Non-Parametric Test (kruskal Wallis) at 5\% threshold and Spearmen's Correlation Test. These analyses were performed using XLSTAT version 2020.5.1 and MINITAB version 19.1.1.0 software.

\section{RESULTS AND DISCUSSION}

Five major groups were obtained from the hierarchical classification at a distance of 6.65 (Fig 1), knowing that the number of clades in the final subdivision was based on the number of subspecies of $V$. sativa L. reported by Quezel and Santa (1962). Some accessions belonging to the same subspecies presented homologous profiles, others identified by the same key displayed ultra-polymorphic profiles. The lowest Euclidian distance $(\mathrm{d}=1)$ is observed between the two accessions 16 and 17 (subsp. obovata), these individuals presented two extra similar profiles with a level of similarity equal to 89.4 and only one variable showing two different modalities, confirming their great rapprochement in the circle of individuals in PCA (Fig 2). On the other side, The greatest Euclidian distance $(\mathrm{d}=6.65)$ observed between the two accessions 1 and 19 (subsp. obovata); these individuals presented two hyper heterogeneous profiles with a level of similarity equal to 29.54 and 22 variables with different modalities. These results are consistent with those obtained by Bechkri and Khelifi (2016) and highlight the taxonomic debates concerning the group $V$. sativa $L$.

In order to study the similarities between individuals, a principal component analysis was carried out on 71 characters coded with ordinal values and ranked from 2 to 6 states (Table 1). 29 characters presented homologous modalities for all accessions and were disqualified. The results of our PCA showed that the first 12 axes had Eigen values greater than 1 and held more than $90 \%$ of the information. In our case only the 2 first axes were maintained in order to build a 2D plan with an inertia imprisonment of around $30 \%$, axis1 (18.33\%) and axis2 (11.48\%).

Among the most explanatory variables having a good correlation with the first factor we distinguished: ClowTL $(r=0.9024)$, CupTL $(r=0.9024)$, CTL $(r=0.7175)$, CHD $(r=0.7124)$, SP $(r=-0.5170)$ and SHD $(r=-0.4915)$ (Fig 2). These results correspond with those cited by Van De Wouw et al. (2003) which shows that the characters that separate the most subspecies are nearly quantitative. According to Mettin and Hanelt (1964), Vicia angustifolia L. and Vicia amphicarpa L. generally possess hairier calyx than other subspecies. Our results, in addition to the results of Bechkri and Khelifi (2016) showed quite the opposite for $V$. angustifolia L. Five main variables participated in building the second factor, 3 of them exhibited a positive correlation: ABBO ( $r=0.745)$, Lsur $(r=0.696)$, HD ( $r=0.658)$. In contrast, WC $(r=-0.694)$ and SC $(r=-0.619)$ provided a negative correlation. These traits confirmed the results cited by Potokina (1997) on the possibility of classifying accessions successfully by their types of coat models. In the light of these results, it was shown that the first factor concerned the length of teeth and pubescence of the calyx depending on the stem pilosity. While, the second factor concerned the patterns of pods and seeds according to their color. These demonstrate the usefulness of these characters for the identification of different Vicia sativa $L$. subspecies.

The results of our Kruskal-Wallis test executed on 29 continuous quantitative traits showed a significant effect of the factor (accessions) for all the attributes used in our study 


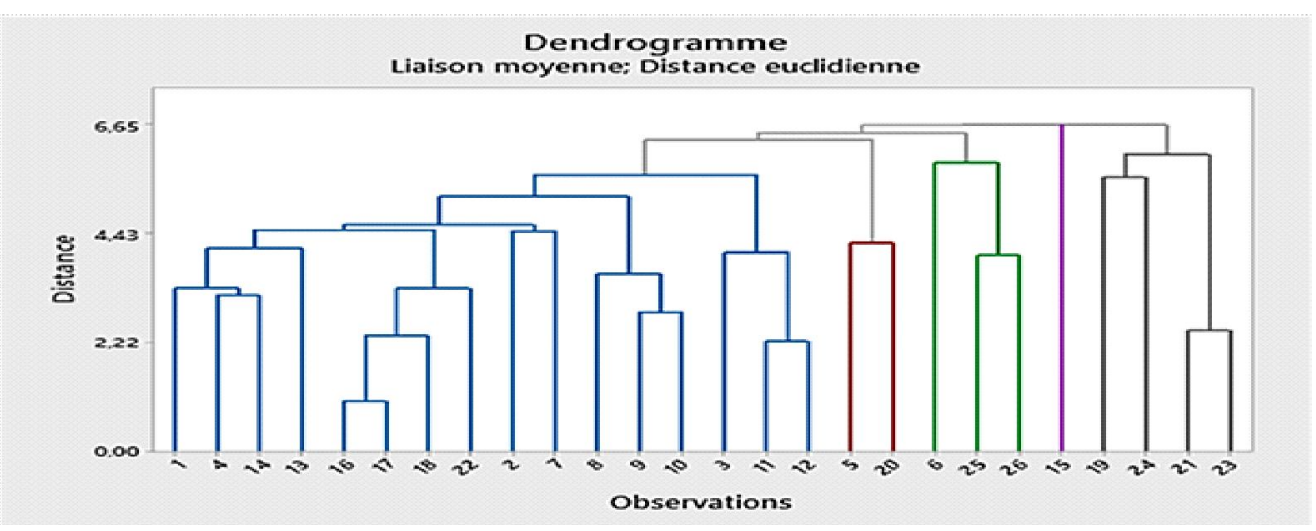

Fig 1: Hierarchical classification of the studied accessions based on morphological traits.

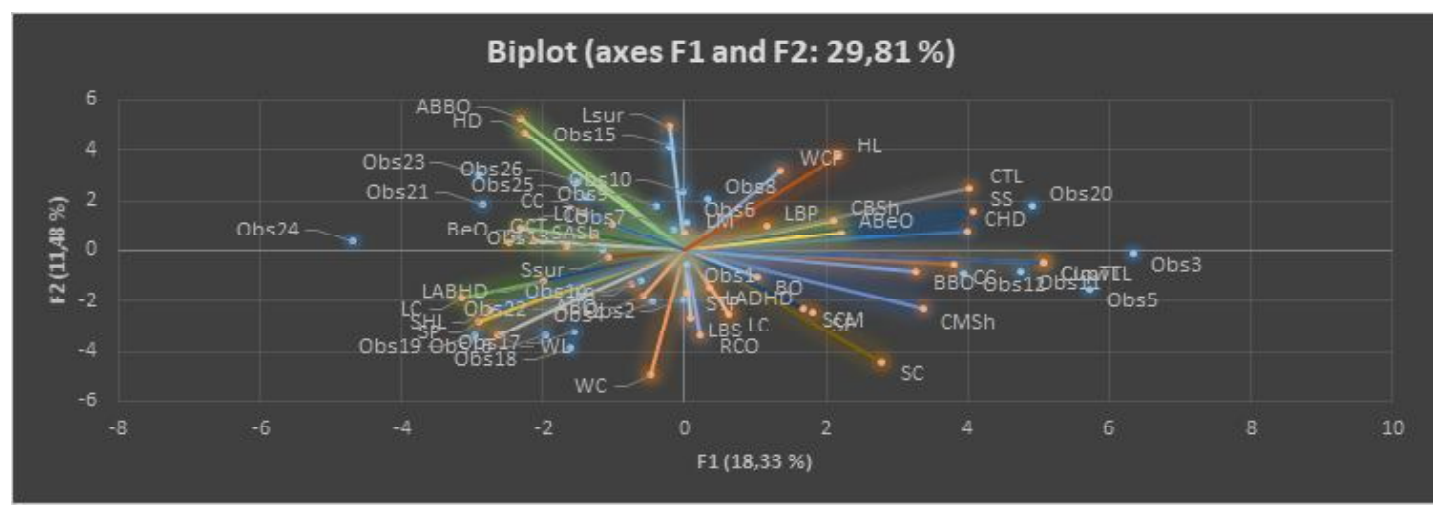

Fig 2: Biplot circle of the principal component analysis.

(Table 1). These genetically diverse accessions can be used as promising parents for hybridization (Singh et al. 2021), to develop superior hybrids with desirable combination of traits (Janghel et al. 2021). Mebarkia et al. (2020) revealed a significant positive relationship between the full flowering stage with grain yield $(r=0.76)$ and aerial biomass $(r=0.69)$ and showed that late varieties are the most productive. The results of our study showed that sample 16 was the late entry for the start of flowering (117d), full flowering (124d), pod formation $(136 \mathrm{~d})$ and full maturity (155d) with moderate to high values for almost all variables. Contrastingly, sample 5 was the earliest for the same stages (101d, 109d, 114d and $138 d)$ with very low values for most of the characters studied. It seems that the late and long period of flowering allows these accessions to escape the late frosts of the region, which negatively affects the fertility of the plant. These results are in line with those obtained by Keating et al. (1991).

The highest plant at harvest (accession14) recorded a measurement equal to $82 \mathrm{~cm}$, while the most dwarf (accession6) exhibited a height equivalent to $36 \mathrm{~cm}$. Mebarkia et al. (2020) revealed a significant positive correlation ( $r=0.62)$ between grain yield and plant height. Our results are in disagreement with these findings and showed that both sample 6 and 14 displayed low grain yield with respectively 1.82 and $5.62 \mathrm{~g} /$ plant. This can be explained by the low values recorded by these two accessions concerning seed size ( 3.19 and $3.58 \mathrm{~mm})$ and the weight of one hundred grain (2.46 and $3.92 \mathrm{~g})$. According to Moles et al. (2005), small-seeded species are able to produce more seeds for a given amount of energy in comparison with large-seeded species. This finding confirmed in our case as the smallest diameter of seeds ( $3.32 \mathrm{~mm}$ ) is attributed to accession 24 (subsp. consobrina) recorded a larger value of NG/P with an average of 7.26.

In exalbuminated seeds like those of vetch, the early stages of radicle elongation seem to depend on reserves accumulated in their own tissues (Hopkins, 1999). This indicate that it is preferable to use large seeds to improve the emergence and survival of plants, especially in areas with harsh environmental conditions (Mao et al. 2015; Dong et al. 2016). The accession 20 (subsp. obovata) presented the largest diameter of seeds $(5.38 \mathrm{~mm})$ with the highest WHS (12.17g). Therefore, it can help breeders working to improve emergence in areas with difficult environmental conditions.

The accession 9 (subsp. obovata) proved to be the most efficient by recording high values for the most of variables with agronomic interest especially grain yield (8.29g/plant), number of pods per plant (17.66), number of seeds per pod (6.13) and weight of hundred grain (7.36g). Hence, direct selection for these traits will lead to the development of desirable high yielding genotypes (Sharma et al. 2021).

Spearman's correlation test showed that soil conductivity followed by elevation and soil organic matter are the characters that most influence the variability of 
Genetic Diversity Associated with Eco-geographical Parameters, Morphological Characteristics and Soil Analyzes of Common...

Table 1: Results of kruskal-Wallis test and descriptive statistics.

\begin{tabular}{lccccccc}
\hline Variable & Mean & S.D & K & Variable & Mean & S.D & K \\
\hline LEN/P & 43,718 & 7,150 & $70,5138^{*}$ & NR & 8,462 & 2,220 & $49,6789^{*}$ \\
WID/P & 6,606 & 1,070 & $73,8315^{*}$ & NN/MS & 15,808 & 2,678 & $41,2292^{*}$ \\
THI/P & 4,7261 & 0,6613 & $66,3667^{*}$ & NPN/MS & 2,7051 & 0,7578 & $50,1886^{*}$ \\
WEI/P & 0,3889 & 0,1287 & $67,4366^{*}$ & DC & 3,1574 & 0,6712 & $40,6152^{*}$ \\
LEN/B & 2,1995 & 0,3507 & $57,5797^{*}$ & ST & 2,0964 & 0,7098 & $44,1653^{*}$ \\
NG/P & 5,751 & 1,512 & $63,1054^{*}$ & PH & 55,99 & 10,73 & $57,6958^{*}$ \\
LEN/S & 4,5331 & 0,6389 & $69,4752^{*}$ & Lpidi & 5,039 & 1,516 & $54,7999^{*}$ \\
WID/S & 4,1615 & 0,5876 & $70,9863^{*}$ & EM & 11,423 & 2,885 & $45,4492^{*}$ \\
THI/S & 3,4302 & 0,4563 & $70,4683^{*}$ & $3 L$ & 25,115 & 4,074 & $55,9827^{*}$ \\
WHS & 5,104 & 2,190 & $70,9895^{*}$ & $5 \mathrm{~L}$ & 34,808 & 4,610 & $60,8439^{*}$ \\
PL & 50,53 & 11,04 & $65,8582^{*}$ & RAM & 42,423 & 5,123 & $61,7034^{*}$ \\
LPN & 6,641 & 0,897 & $59,1979^{*}$ & SF & 109,46 & 5,33 & $70,1238^{*}$ \\
PN/P & 14,282 & 5,096 & $44,4268^{*}$ & FF & 116,92 & 4,95 & $66,1011^{*}$ \\
GY/P & 4.0612 & 2.2559 & $52.5138^{*}$ & PF & 127,69 & 6,47 & $68,0184^{*}$ \\
PN/MS & 3,577 & 1,243 & $52,8592^{*}$ & MT & 147,08 & 5,02 & $69,2416^{*}$ \\
\hline
\end{tabular}

Continuous quantitative variables:

LEN/P: Length of pod. WID/P: Width of pod. THI/P: Pod thickness. WEI/P: Pod weight. LEN/B: Beak length. NG/P: Number of grains per pod. LEN/S: Seed length. WID/S: Seed width. THI/S: Seed thickness. WHS: Weight of one hundred grain. PL: Petiole length. LPN: Leaflet pair number. PN/P: Pod number per plant. PN/MS: Pod number in the main stem. NR: Ramification number. NN/MS: Number of node per main stem. NPN/MS: Number of productive node per main stem. DC: Collar diameter. ST: Stem thickness. PH: Plant height. Lpidi: Pedicel length. EM: Emergence. 3L: 3 leaf. 5L: 5 leaf. RAM: Ramification. SF: Start flowering. FF: Full flowering. PF: Pod formation. MT: Maturity. SD: Standard deviation. K: observed value. ${ }^{*}=$ Significant at 0.05 .

Morphological traits coded with ordinal values

SB: Stem branching; STF: Stem form; SEC: Stem edge color; SP: Stem pubescence; SHE: Stem hair elevation; SHL: Stem hair length; SNC: Stem node color; CRS: Creeping rootstock (rhizome); LRSh: Leaflets relative shape; LRS: Leaflets relative size; LCo: Leaflet consistence; LAC: Leaflet abaxial color; LLP: Lower leaflet position; LSh: Leaflet shape; LBP: Leaflet broadest point; LAS: Leaflet apex shape; LAD: Leaflet apex dentate; LB: Leaflet base; LM: Leaflet margin; LMH: Leaflet margin hairness; LADHD: Leaflet adaxial hair density; LHE: Leaflet hair elevation; LABHD: Leaflet abaxial hair density; NFI: Number of flowers per inflorescence; FL: Flower length; PL: Peduncle length; SCP: Standard color pattern; SC: Standard color; SASh: Standard apex shape; STP: Standard pubescence; WCP: Wing color pattern; WC: Wing color; WLS: Wing length; KC: Keel color; KCP: Keel color pattern; KL: Keel length; CBSh: Calyx base shape; CMSh: Calyx mouth shape; CH: Calyx hairness; CHD: Calyx hair density; CC: Calyx color; CTL: Calyx teeth length; CupTL: Calyx upper teeth length; ClowTL: Calyx lower teeth length; CupTSh: Calyx upper teeth shape; ClowTSh: Calyx lower teeth shape; LS: Legume shape; LP: Legume pubescence; Lsur: Legume surface; LC: Legume color; LBS: Legume beak shape; LST: Legume stalk; LT: Legume torulose; HD: Hair density; RCO: Red color ornamentation; SS: Seed shape; SCS: Seed cross-section; Ssur: Seed surface; SF: Seed finish; SC: Seed color; SCM: Seed color mottling; GCT: Seed color of testa; BO: Brown ornamentation; ABO: Area of brown ornamentation; BeO: Beige ornamentation; $\mathrm{ABeO}$ : Area of beige ornamentation; $\mathrm{BBO}$ : Blue black ornamentation; $\mathrm{ABBO}$ : Area of blue black ornamentation; $\mathrm{CC}$ : Cotyledon color; HL: Hilum length; HC: Hilum color.

morphological traits. However, the use of a large number of accessions for each site with putting emphasis on these characters is necessary in order to confirm the resulting model.

\section{CONCLUSION}

The morphological and eco-geographical characterization of 26 accessions belonging to the $V$. sativa $L$. species collected from different localities in Sétif province shows great intra-specific genetic variability highlighting the importance of local ecotypes and the need to establish conservation programs for this genetic heritage by referring to the habitat preferences of each accession and their geographical distributions that have been demonstrated in this work. It is known that climate change affects drastically the region especially the central and southern region where drought is becoming a chronic problem. These genetic resources present an important source of variability in the various breeding programs for creation of drought and coldtolerant varieties considering the difficult climate conditions of the province especially during the flowering period, which often coincides with late frosts and during the filling of the grain, which is often exposed to drought. The magnitude of the variability in the phenological stages of accessions studied can help breeders reach compromises. Further characterization of these accessions is recommended using both biochemical and molecular techniques to enhance their value and facilitate their use by breeders. 


\section{REFERENCES}

Annese, V., Cazzato, E., Corleto, A. (2006). Quantitative and qualitative traits of natural ecotypes of perennial grasses (Dactylis glomerata L., Festuca arundinacea Schreb., Phalaris tuberosa L., Brachypodium rupestre (Host) R. et $\mathrm{S}$. collected in southern Italy. Genetic Resources and Crop Evolution. 53: 431-441.

Bechkri, S. and Khelifi, D. (2016). Variation in Vicia sativa s.l. from Algeria based on morphological characters and ecogeographic parameters. Genetic Resources and Crop Evolution. 64: 815-832.

Blum, A. (1966). The influence of plant density on the morphological characters and seed production of common vetch (Vicia sativa L.). Experimental Agriculture. 2: 61-67.

Dong R., Dong D.K, Shao, K.Z. et al. (2016). The digital evaluation of the cracking force of common vetch with the different characteristics of pod shattering. (In Chinese with English abstract.). Pratacultural Science. 33: 2511-2517.

Dong, R., Liu, Z.P., Dong, D.K., Luo, D., Zhou, Q., Chai, X.T., Zhang, J.Y., Xie, W.G., Liu, W.X., Dong, Y., Wang, Y.R., Liu, Z.P. (2017). Transcriptome analyses reveal candidate pod shattering associated genes involved in the pod ventral sutures of common vetch (Vicia sativa L.). Frontiers in Plant Science. 8: 649.

Dong, R., Shen, S.H., Jahufer, M.Z.Z., Dong, D.K. et al. (2019). Effect of genotype and environment on agronomical characters of common vetch (Vicia sativa L.). Genetic Resources and Crop Evolution. https://doi.org/10.1007/ s10722-019-00789-3.

Erskine, W., Smartt, J., Muehlbauer, F.J. (1994). Mimicry of lentil and the domestication of common vetch and grass pea. Economic Botany. 48: 326-332.

Firincioglu, H.K., Erbektas, E., Dogruyol, L. et al. (2009). Phenotypic variation of autumn and spring-sown vetch (Vicia sativa ssp.) populations in central Turkey. Spanish Journal of Agricultural Research. 7: 596-606.

Fracchiolla, M., Lasorella, C., Laudadio, V., Cazzato, E. (2018). Trifolium mutabile as new species of annual legume for mediterranean climate zone: First evidences on forage biomass, nitrogen fixation and nutritional characteristics of different accessions. Agriculture. 8: 113.

Hopkins, W.G. (1999). Introduction to Plant Physiology, (2 $2^{\text {nd }}$ Edn.). John Wiley and Sons, Inc. pp. 514.

Janghel, D.K., Kumar, K., Kumar, M., Chhabra, A.K. (2021). Genetic diversity assessment in chickpea (Cicer arietinum L.) through agro-morphological and ISSR molecular markers. Legume Research. 7: 751-758.
Keatinge, J.D.H., Asghar, A., Roidar, K.B., Abd el moneim, A.M., Ahmed, S. (1991). Germplasm evaluation of annual sown forage legumes and environmental conditions marginal for crop growth in highland of West Asia. Journal of Agronomy and Crop Science: 45-87.

Mao, Z.X., Hua, F., Nan, Z.B., Wan, C.G. (2015). Fatty acid, amino acid and mineral composition of four common vetch seeds on Qinghai-Tibetan plateau. Food Chemistry. 171: 13-18.

Mebarkia, A., Abdelguerfi, A. (2007). Etude du potentiel agronomique de trios especes de vesces (Vicia spp.) et variabilité dans la région semi-aride de Sétif (Algérien). Fourrages. 192: 495-504.

Mebarkia, A., Bougrine, H., Badache, F., Mahmah, S. (2020). Etude de la production et de la phénologie de dix variétés de Vesce (vicia) du réseau maghrébin dans les hautes plaines Sétifiennes (Algérie). Fourrages. 241: 57-64.

Mettin, D., Hanelt, P. (1964). Cytosystematische Untersuchungen in der Artengruppe um Vicia sativa L. I. Die Kulturpflanze. 12: $163-225$

Moles, A.T., Ackerly, D.D., Webb, C.O., Tweddle, J.C., Dickie, J.B., Westoby, M. (2005). A brief history of seed size. Science. 307: 576-580.

Potokina, E.K. (1997). Vicia sativa L. aggregate (Fabaceae) in the flora of the former USSR. Genetic Resources and Crop Evolution. 44: 199-209.

Quézel, P., Santa, S. (1962). Nouvelle flore de l'Algérie et des régions méridionales. Tome 1 . Editions du centre national de la recherche scientifique. Paris, pp. 524-531.

Sattell, R., Dick, R., Luna, J., Peachey, R.E. (1998). Common vetch (Vicia sativa L.). Corvallis Ext. Serv., Oregon State Univ, Corvalis.

Sharma, R.N., Johnson, P.L., Nanda, H.C., Sao, A., Sarawgi, A.K., Umesh, Verma, S.K., Prabha, N., Singh, A.K. (2021). Genetic variability, character association and coheritability for yield traits over the locations in chickpea (Cicer arietinum L.). Legume Research. 7: 859-863.

Singh, S., Sharma, V.R., Nannuru, V.K.R., Singh, B., Kuma, M. (2021). Phenotypic diversity of pea genotypes (Pisum sativum L.) based on multivariate analysis. Legume Research. 8: 875-881.

Upov, (1988). Principes directeurs pour la conduite de l'examen des caractères distinctifs de l'homogénéité et de la stabilité. DOC No.TG/32/6 (21.10.1988).

Van de Wouw, M., Maxted, N., Bria Fordlioyd, B.V. (2003). Agro morphological characterization of common vetch and its close relatives. Euphytica. 130(2): 281-292. 